\title{
Os desafios da eqüidade: reestruturação e desigualdades de gênero e raça no Brasil ${ }^{*}$
}

\begin{abstract}
Nadya Araújo Guimarães**
\section{Resumo}

O texto documenta a existência de padrões distintos de desigualdades nos rendimentos auferidos no trabalho entre grupos de sexo e cor, no Brasil, analisando dados da Pesquisa Nacional por Amostra de Domicílios para os anos de 1989 e 1999. Argumenta em favor da importância dos demarcadores inscritos no corpo como elementos explicativos importantes, embora não exclusivos, das desigualdades salariais documentadas, procura isolar prováveis indícios de discriminação racial e/ou de gênero, controlando estatisticamente o efeito de outros possíveis determinantes das desigualdades nos rendimentos. Finalmente, reflete sobre os elos entre desigualdade, discriminação e intolerância nos ambientes de trabalho no Brasil.
\end{abstract}

Palavras-chave: Desigualdades salariais, Racismo, Sexismo, Trabalho Industrial.

\footnotetext{
" Nesse texto, retomo e complemento alguns dos achados empíricos apresentados em relatório preparado, sob os auspícios da FINEP, CUT-DESEP e CEBRAP, para o Projeto de Pesquisa e Formação Sindical "Reestruturação Produtiva, Política Industrial e Contratação Coletiva nos Anos Noventa: As Propostas dos Trabalhadores" (GUIMARÃES, Nadya Araújo e CONSONI, Flavia Luciane. As Desigualdades Reestruturadas - Um olhar sobre os diferenciais de sexo e raça no acesso ao trabalho em setores selecionados da atividade industrial. S.Paulo, agosto de 2000). Agradeço o apoio à preparação dos dados que recebi, em diferentes momentos, de Paulo Henrique da Silva e Marcus Vinicius Farbelow. Registro também meus agradecimentos a Flavia L. Consoni e Ciro Biderman, parceiros na concepção das estratégias de análise. Finalmente, devo valiosos comentários e sugestões a Helena Hirata, Cristina Bruschini, Laís Abramo e Maria Rosa Lombardi. A nenhuma dessas pessoas, é claro, cabe qualquer responsabilidade intelectual pelos riscos interpretativos que assumo ao longo do texto. Recebido para publicação em outubro de 2001.

*** Professora do Departamento de Sociologia da Universidade de São Paulo.
} 
Os desafios da eqüidade

Challenges for Equity:

Economic Restructuring and Race-Gender Inequalities in Brazil

\begin{abstract}
Different patterns of wage inequality prevail among black men, black women and white women vis-à-vis white men. Analyzing data from the National Household Sample Survey (1989 and 1999), and controlling over other possible explaining variables (like individual assets and features of labor market structure) the author claims that adscription is an important (although not exclusive) source of wage differentiation among sex and race groups. Should we expect that inequalities (grounded on discriminatory practices) could lead to the emergence of intolerance and violence at the workplaces?
\end{abstract}

Key words: Wage Inequalities, Race Discrimination, Gender Discrimination, Labor Market. 
Os estudos brasileiros sobre reestruturação industrial, em sua maioria, pouca atenção têm costumado prestar às diferenças que se estabelecem entre grupos de gênero e étnico-raciais, quanto ao acesso e às formas de sua inclusão nos ambientes produtivos em processo de transformação tecnológica e/ou organizacional. Nisso se assemelham à forma usual pela qual a sociologia, em geral, e os estudos sociais do trabalho, em especial, costumeiramente construíram suas análises sobre as transformações recentes nos processos de trabalho, $e$ a negociação coletiva de tais mudanças.

A que atribuí-lo? À irrelevância empírica do tema? Certamente que não, e penso poder ilustrá-lo com este trabalho. À ausência de atores sociais capazes de atrair a atenção para as vicissitudes da sua inserção social? Tampouco, tendo em vista a visibilidade, crescente nas últimas décadas, no Brasil, dos movimentos negros e do movimento feminista. ${ }^{1}$ À escassa legitimidade social das linhas de desigualdade de gênero e/ou étnico-racial? Talvez; isto porque mesmo sendo patentes as desigualdades e progressivamente mais visíveis os movimentos em torno da sua superação, a crença em que somos um exemplo de "democracia racial" tem levado a que a sociedade brasileira tenda a explicar o fado dos negros pela sua condição de pobreza, antes que pela discriminação alimentada no racismo.

Nesse sentido, é patente a invisibilidade das barreiras, de sexo $e$ de cor, que vigem nos ambientes de trabalho reestruturados, mesmo quando observamos atores com longa tradição de negociar pautas diversas de interesses, ou de criar novas instituições talhadas para tal. ${ }^{2}$ Não se trata aqui de avançar

1 Guimarães, Antonio Sergio e Huntley, Lynn. Tirando a Máscara - Ensaios sobre o Racismo no Brasil. São Paulo, Paz e Terra, 2000.

${ }^{2}$ É fato que os movimentos feminista e negro se ressentem do pouco espaço e receptividade que parecem encontrar no âmbito das organizações sindicais. Recentemente, co-participando em projeto dirigido ao tema dos efeitos da reestruturação produtiva sobre as oportunidades de negros e mulheres no $\mathrm{ABC}$, 
Os desafios da eqüidade

nesse tipo de consideração, conquanto convenha chamar a atenção para a forma como problemas de eqüidade, como estes, podem estar invisibilizados, porque subsumidos em discursos de tipo essencialista.

Tal essencialismo, por vezes, ganha encarnação na forma como se representa a natureza dos processos de trabalho. Assim, ao conduzirmos a pesquisa de campo em ambientes industriais, com freqüência, nos deparamos com a referência (seja pelas gerências, seja por trabalhadores, seja por militantes sindicais) de que tais empresas são "feitas para machos". E por que? Por requererem coragem, destemor frente a riscos $e$ inteira disponibilidade para $\mathrm{o}$ trabalho em regime de turnos, componentes considerados como "naturais" da constelação do "masculino". Por isto mesmo, parece "naturalmente compreensível" a ausência de mulheres em ambientes como esses, tidos como "essencialmente masculinos".

foi possível verificar como essa ainda é uma área crítica, que desafia mesmo alguns dos sindicatos usualmente citados por seu caráter inovador e por sua capacidade de assimilar novas bandeiras e possibilidades reivindicatórias (ver Guimarães, Nadya Araújo; Leite, Márcia de Paula; Bento, Maria Aparecida; SoARES, Vera; ABRAmo, Laís; LomBARDI, Maria Rosa; Consoni, Flavia. Gestão Local, Empregabilidade e Eqüidade de Gênero e Raça: Um Experimento de Política Pública na Região do ABC Paulista. Relatório da Fase 1, São Paulo, FAPESP/CEBRAP/Prefeitura Municipal de Santo André/CEERT/ELAS, agosto de 2000). Isso para não falarmos no quão recente é a criação, em alguns poucos sindicatos, de grupos de trabalho, departamentos e iniciativas similares (mais ou menos institucionalizadas), voltadas para incorporar à pauta da militância sindical a temática das desigualdades de oportunidades e da discriminação racial. Compare-se tais iniciativas (e dificuldades) atuais com aquelas iniciativas pretéritas, empreendidas por coletivos de mulheres e tão bem analisadas pela sociologia brasileira do trabalho de quase duas décadas atrás (ver, por exemplo, HUMPHREY, John. Sindicato, um mundo masculino. Novos Estudos Cebrap. Vol.2, n.1, abril de 1983, pp. 47-52). Mas, há que ter também em conta que tal dificuldade não é peculiar ao Brasil, sendo reconhecida em outros estudos para a América Latina. Cf. ABRAMO, Laís e RANGEL, Marta. Negociación colectiva y equidad de género en el contexto del MERCOSUR. Santiago, mimeo., marzo de 2002, 24 pp. 
Nadya Araújo Guimarães

A natureza dos contextos de trabalho encontraria, desse modo, uma tradução imediata na natureza daqueles que a eles se incorporariam.

Mas tal essencialismo pode também aparecer encarnado na forma pela qual se representa a sociedade brasileira, aludindo a um caráter único, a uma matriz cultural irredutível, internalizada na consciência coletiva por meio da idéia de que somos uma "democracia racial". Esse seria um dos cimentos da nossa identidade enquanto nação, um dos nossos mitos fundadores, um dos demarcadores básicos da nossa auto-identificação como brasileiros. Por isto mesmo, seria próprio da nossa forma de ser a diluição das diferenças, tensões, intolerâncias ou discriminações de cunho étnico-racial. $\mathrm{E}$, se elas não se exprimem nos locais de trabalho, isto nada mais é que um resultado "natural" da nossa de construção identitária, dado o nosso ideário de nação mestiça.

Essa invibilização das diferenças, desigualdades $e$ discriminações, sustentada em argumentos sobre supostas "essências" (vindas da natureza do trabalho ou da natureza da sociedade) encontram uma curiosa continuidade na representação sobre a modernidade industrial que se difundiu amplamente a partir dos chamados "novos paradigmas de organização e uso do trabalho". Para os afeitos aos estudos sobre as recentes transformações nos ambientes produtivos sobram assertivas em torno da modernidade que os passaria a caracterizar. Forjou-se, ao longo dos últimos anos, uma espécie de "território de senso comum" que teve sua espinha dorsal no discurso empresarial, mas com ecos na academia e também no movimento sindical.

De acordo com esse discurso, as mudanças recentes teriam introduzido um novo padrão de produzir e também de gerenciar o trabalho, no qual destacava-se a crença em que o ingresso, a sobrevida e a mobilidade do trabalhador nos novos ambientes de trabalho dependeriam, em grande medida, da sua capacidade de promover um contínuo processo de desenvolvimento de competências (da mais diversa ordem, e que não cabe aqui detalhar). Assim, ingresso, permanência e mobilidade - 
Os desafios da eqüidade

sobrevivência nos postos de trabalho, enfim - passariam a estar ligados à posse e ao contínuo aperfeiçoamento de um conjunto de "ativos".

Mas, qual a novidade, visto que as oportunidades ocupacionais sempre foram seletivas e que tal seleção sempre teve em conta qualidades e qualificações, "ativos" individualmente possuídos? Exploremos um pouco mais esse território comum. As novidades tecnológicas e organizacionais andariam de braços dados com um conjunto de conhecimentos e atitudes, requeridos dos trabalhadores aptos a sobreviver nos ambientes reestruturados. Um conjunto de competências, diz o credo; cognitivas, mas também atitudinais. Dito de outro modo, poderse-ia afirmar que ingresso, permanência e mobilidade nos postos de trabalho passariam a resultar de um novo conjunto de atributos socialmente valorados, cuja novidade residiria no seu caráter aquisitivo, por oposição às formas adscritivas que antes prevaleciam. Assim, universalismo (associado à aquisição) - e não o particularismo (associado a adscrição) - deveria reger as decisões sobre recrutar, avaliar e remunerar os trabalhadores. Escolaridade, qualificação, compromisso, atitude cooperativa, envolvimento com os objetivos da empresa, e outros componentes deste cardápio, são ativos cujo acesso (supõe o argumento) estaria aberto a todos; daí o universalismo explicitamente propugnado pelas novas formas de gerenciar o trabalho. Sua posse dependeria unicamente do desempenho individual.

Mas, por que sugeri acima que haveria uma continuidade entre, por um lado, aqueles argumentos essencialistas, que invizibilizam as formas de desigualdade e discriminação nos locais de trabalho, e, por outro, os argumentos gerenciais, que caracterizam a novidade da gestão do trabalho nesses mesmos ambientes, uma vez reestruturados? Porque, arriscaria sugerir, o discurso gerencial sobre os novos paradigmas de organização $e$ gestão do trabalho também se assenta num essencialismo: o que confere à modernidade (gerencial, no caso) um conteúdo de irredutível universalismo, fundado na gestão das competências 
Nadya Araújo Guimarães

adquiridas e adquiríveis pelo trabalhador. Nele, naturalmente, não deveria haver lugar para o particularismo que sustenta toda $e$ qualquer forma de discriminação, de preconceito ou de intolerância.

\section{Diferenças e desigualdades}

Ora, se houve um setor, no mundo do trabalho no Brasil, onde essa nova cultura normativa fez furor (até porque nele se originou), esse setor foi o da indústria. Não seria, pois, impertinente indagarmos que se passa com a população que acorre ao mercado de trabalho, e particularmente com os trabalhadores industriais, nos anos de intensa e recente reestruturação, se os observamos sob o prisma das diferenças de incorporação de negros e de mulheres. Reestruturam-se as desigualdades? Em que direção?

Tomando dados para o período compreendido entre 1989 e 1998/99, e lançando mão da mais abrangente pesquisa amostral domiciliar brasileira, a Pesquisa Nacional por Amostra de Domicílios - PNAD, vê-se uma curiosa permanência no que concerne às desigualdades: a indústria ainda é essencialmente masculina e branca, mesmo após os 10 últimos anos de intensa reestruturação, quando muito se alterou no perfil do trabalhador "sobrevivente". ${ }^{3}$

Mas, será essa característica uma expressão do que se passa no mercado de trabalho como um conjunto? Definitivamente, não. Nas duas últimas décadas, em especial, cresceu de modo

\footnotetext{
3 Para descrever a persistência dessas desigualdades mesmo em contextos submetidos a intensa reestruturação, como foi o caso do trabalho fabril nos anos 90, tomo a base de dados da PNAD em dois marcos de tempo. O ano de 1989 simbolizará o momento que antecede à intensificação das mudanças sob o influxo da conjunção entre crise, ajuste macro-econômico e mudanças microorganizacionais. Os anos de 1998 e 1999, últimos para os quais dispunha de dados da PNAD, serão usados como ponto de chegada mais atual desses processos.
} 
Os desafios da eqüidade

significativo a presença de mulheres no mercado de trabalho. Esse movimento, entretanto, não tem correlato na indústria, onde causa espécie a estabilidade da composição do emprego segundo o sexo (Tabela 1$)^{4}$

Tabela 1

Composição por sexo da população ativa e dos ocupados na indústria, em 1989 e 1998

\begin{tabular}{l|cc|cc}
\hline & \multicolumn{2}{|c|}{ PEA } & \multicolumn{2}{c}{ Ind. Transformação } \\
& 1989 & 1998 & 1989 & 1998 \\
\hline Mulheres & 35.2 & 42.2 & 28.3 & 28.2 \\
Homens & 64.8 & 57.8 & 71.7 & 71.8 \\
\hline
\end{tabular}

Fonte: PNAD/IBGE

No que diz respeito aos negros ${ }^{5}$, sua presença, de há muito marcante na atividade econômica, aumenta apenas muito

\footnotetext{
4 Para manter a fluência do argumento, evitando entrecortá-lo com referências excessivas a números, destaco, em negrito, no corpo desta como das subseqüentes tabelas, os números mais significativos para sustentar aquilo que se afirma ao longo do texto.

5 A PNAD apura a condição racial através da aplicação de um quesito sobre cor, com alternativas previamente estruturadas segundo o sistema oficial de classificação racial. A resposta obtida resulta da auto-classificação do entrevistado, segundo a estrutura previamente fornecida de alternativas. O que aqui referiremos como "negros" equivale à soma dos que se auto-identificaram como "pretos" e como "pardos". Para os demais, que poderíamos considerar de fato como não-negros, estamos usando a denominação de "brancos". Por certo, as denominações escolhidas acertam, por assim dizer, no atacado, embora possam ser imprecisas no varejo. Explico: elas acertam, creio, porque aludem aos contingentes majoritariamente abarcados em cada grupo; convém, entretanto, dizer que estes contingentes não são os únicos. No que concerne ao grupo dos "brancos", a escolha tem em conta o seu peso decisivo entre os demais grupos raciais ("amarelos" e "indígenas"), também aí abarcados. No que concerne ao grupo dos "negros" (resultado da soma de "pretos" e "pardos"), é também importante ressaltar que nem sempre se pode supor que os "pardos" sejam afrodescendentes (o que é cabível esperar entre os que se auto-denominam "pretos"); muitos deles podem ser mestiços de outras descendências (brancos e
} 
ligeiramente quando se intensifica o processo de reestruturação da indústria (Tabela 2).

Tabela 2

Composição racial da população ativa e dos ocupados na indústria, em 1989 e 1998

\begin{tabular}{l|cc|cc}
\hline & \multicolumn{2}{|c|}{ PEA } & \multicolumn{2}{c}{ Ind. Transformação } \\
& 1989 & 1998 & 1989 & 1998 \\
\hline Negros & 42.9 & 42.7 & 35.9 & 36.7 \\
Brancos & 57.1 & 57.3 & 64.1 & 63.3 \\
\hline
\end{tabular}

Quando analisamos simultaneamente diferenciais de inclusão de grupos de sexo e de cor, no conjunto da PEA e na indústria, as tendências se aclaram um pouco melhor (Tabela 3).

Tabela 3

Distribuição dos indivíduos em atividade no mercado de trabalho brasileiro, segundo gênero e raça, em 1989 e 1998

\begin{tabular}{l|cc}
\hline & \multicolumn{2}{|c}{ PEA } \\
& 1989 & 1998 \\
\hline Mulher Negra & 14.6 & 18.7 \\
Mulher Branca & 20.6 & 23.5 \\
Total Mulheres & 35.2 & 42.2 \\
Homem Negro & 28.3 & 26.6 \\
Homem Branco & 36.6 & 31.1 \\
Total Homens & 64.8 & 57.8 \\
\hline
\end{tabular}

Fonte: PNAD/IBGE

indígenas, por exemplo), sendo tal ocorrência significativa em algumas partes do país, como é o caso da Região Norte. Entretanto, pela ênfase que nossa análise coloca na questão da discriminação no trabalho industrial, e dada a geografia da indústria brasileira, acredito que tal fonte de erro possa ser considerada de efeito desprezível para as conclusões a que se pretende aqui chegar. 
Os desafios da eqüidade

Uma vez mais, podemos ver que aquilo que se passa na indústria é, em alguma medida, distinto do que se passa no mercado de trabalho como um conjunto, onde:

(i) se as mulheres crescem de modo ponderável à sua participação no mercado de trabalho, este crescimento é maior justamente entre as mulheres negras;

(ii) já a redução do peso dos homens na população ativa é sustentada, sobretudo, por um movimento de saída à inatividade de homens brancos, que parecem ter a possibilidade de negociar melhores condições para a sua inclusão, mesmo quando isto importa em estar fora do mercado de trabalho.

$\mathrm{Na}$ indústria (Tabela 4) as tendências parecem ser distintas:

(i) o suave aumento da participação dos homens tem como correlato a maior inclusão de homens negros na atividade industrial;

(ii) já a ligeira redução no peso das mulheres parece esconder o fato de que cresce a participação das trabalhadoras brancas, a indicar um movimento de "embranquecimento" da população feminina ocupada no trabalho fabril.

Tabela 4

Distribuição da força de trabalho na indústria de transformação, segundo gênero e raça, em 1989 e 1998

\begin{tabular}{l|cc}
\hline & \multicolumn{2}{|c}{ Ind. Transformação } \\
& 1989 & 1998 \\
\hline Mulher Negra & 10.1 & 9.6 \\
Mulher Branca & 18.2 & 18.6 \\
Total Mulheres & 28.3 & 28.2 \\
Homem Negro & 25.9 & 27.1 \\
Homem Branco & 45.9 & 44.7 \\
Total Homens & 71.7 & 71.8 \\
\hline
\end{tabular}

Fonte: PNAD/IBGE

Ou seja, diferenciais importantes parecem incidir sobre as condições de acesso de mulheres - especialmente de mulheres 
negras - ao trabalho industrial. Isso está a sugerir que algo mais requer ser observado. Não se trata, unicamente, de reconhecer que a indústria seja um mundo que dá preferência aos atributos da masculinidade. Mais que isto, vemos que, mesmo quando o setor se torna mais permeável ao ingresso de mulheres, outra forma de seletividade se combina, também baseada na adscrição, fazendo com que a chance de ingresso se torne maior quando se trata de mulheres brancas.

Anteriormente, Abreu, Jorge e Sorj ${ }^{6}$, lançando mão de dados domiciliares, haviam assinalado uma importante segmentação no acesso feminino ao mercado de trabalho, diferenciando as mulheres incorporadas em postos registrados $e$ protegidos, das que permanecem no âmbito do trabalho precário $e$, mais das vezes, no serviço doméstico. A distribuição das trabalhadoras entre os "bons" e "maus" empregos, conforme bem reconheceram as autoras, tinha um claro viés racial: enquanto que as mulheres brancas eram dominantes nos primeiros, as negras eram amplamente majoritárias nos segundos. Mais recentemente, Bruschini e Lombardi ${ }^{7}$ exploraram, para o caso brasileiro, a tendência à polarização da inserção feminina, confirmando-a para o caso das ocupações no mercado dos empregos formalmente registrados, à luz de dados fornecidos pelas empresas. Entretanto, aqui argumento que, dentro de um mesmo setor da atividade econômica, essa heterogeneidade volta a se exprimir, mesmo em condições onde a cultura normativa do trabalho indicaria que as qualidades aquisitivas (antes que as adscritivas) deveriam presidir

\footnotetext{
6 ABreu, Alice; Jorge, Angela; SoRJ, Bila. Desigualdade de gênero e raça. O informal no Brasil em 1990. Estudos Feministas, nº especial, $2^{\circ}$ sem. 1994.

7 BRUSCHINI, Cristina e LombARdI, Maria Rosa. A bipolaridade do trabalho feminino no Brasil contemporâneo. Cadernos de Pesquisa, no 110. São Paulo, Fundação Carlos Chagas, julho de 2000. Ver também: BRusCHINI, Cristina e LOMBARDI, Maria Rosa. Mulheres e homens no mercado de trabalho brasileiro. Um retrato dos anos noventa. In: MARUANI, Margaret. (org.), As Novas Fronteiras da Desigualdade: Homens e mulheres no mercado de trabalho. São Paulo, SENAC, 2002.
} 
Os desafios da eqüidade

os movimentos de incorporação e mobilidade nos postos de trabalho.

Quando observamos o que se passa com as condições sob as quais homens e mulheres, negros e brancos, são incluídos no trabalho industrial, vemos que outras desigualdades se manifestam. Os diferenciais de salário são um exemplo eloqüente. Tomamos, numa primeira aproximação, uma simples razão entre rendimentos médios, segundo grupos de sexo e cor.

Como se pode verificar na Tabela 5 , importantes diferenciais de rendimentos separam negros e brancos, sejam homens, sejam mulheres. Um trabalhador ou trabalhadora industrial, se for branco (ou branca), recebe pelo menos 1,7 vezes o rendimento médio de um trabalhador ou trabalhadora industrial, se este (ou esta) for negro (ou negra). E se a distância contida nessa razão parece se reduzir entre as mulheres (passando de 1,9 em 1989 para 1,7 em 1998), ela permanece inalterada (e inalteradamente a mais alta) entre os homens: se brancos, eles percebem duas vezes mais, em média, pelo trabalho industrial, que se forem negros. ${ }^{8}$

Tabela 5

Diferenciais de salário, por sexo segundo a cor, na indústria de transformação entre 1989 e 1998

\begin{tabular}{l|lll|lll}
\hline & \multicolumn{3}{|c|}{ Mulheres } & \multicolumn{3}{c}{ Homens } \\
& Negras & Brancas & B/N & Negros & Brancos & B/N \\
\cline { 2 - 8 } 1989 & 417.5 & 801.8 & 1.9 & 803.5 & 1571.7 & 2.0 \\
1998 & 263.9 & 438.1 & 1.7 & 393.9 & 790.3 & 2.0 \\
\hline
\end{tabular}

Fonte: PNAD/IBGE

\footnotetext{
${ }^{8}$ Nesse momento, reflito sobre a hierarquia dos salários nominais médios, numa primeira aproximação à questão das diferenças; por isto mesmo, as comparações só fazem sentido dentro de um mesmo ano, e nunca entre eles. Em seguida, tornarei mais complexo o argumento e refinada a demonstração.
} 
Nadya Araújo Guimarães

Esses dados, para a indústria, reiteram o achado de outros autores $^{9}$ no sentido de uma redução dos níveis de desigualdade salarial entre sexos. Apesar disto, tais desigualdades, na indústria, ainda permanecem elevadas. Em 1989, o salário médio das mulheres era $52 \%$ do salário dos homens; nove anos depois, em 1998, os ganhos relativos ainda o deixam equivalendo a menos que $2 / 3(59.2 \%)$ dos rendimentos dos homens.

Quando associamos sexo e cor, parece configurar-se uma hierarquia de rendimentos entre os ocupados na indústria, que se expressa em três situações, as quais, grosso modo, se aproximam daquela encontrada em outros estudos para a população economicamente ativa como um conjunto ${ }^{10}$ :

i. No topo estão os homens brancos, invariavelmente respondendo pelos mais altos salários;

\footnotetext{
${ }^{9}$ Ver na literatura sociológica: BRUSCHINI, Cristina. Gênero e Trabalho no Brasil: novas conquistas ou persistência da discriminação? (Brasil, 1985 - 1995). In RochA, Maria Isabel Baltar da. (org.) Trabalho e Gênero - Mudanças, Permanências e Desafios. São Paulo, Editora 34, 2000; BRUSCHINI, C. e LOMBARDI, M. R. A bipolaridade do trabalho feminino no Brasil contemporâneo... Op. cit.; Na literatura da economia do trabalho: LEME, Maria Carolina da Silva e WAJNMAN, Simone. Tendências de coorte nos diferenciais de rendimento por sexo. In: HENRIQUES, Ricardo. (org.) Desigualdade e Pobreza no Brasil. Rio de Janeiro, IPEA, 2000, pp 251-270; SOARES, Sergei Suarez Dillon. O Perfil da Discriminação no Mercado de Trabalho - Homens Negros, Mulheres Brancas, Mulheres Negras. Textos para Discussão, $\mathrm{n}^{\circ} 769$, Rio de Janeiro, IPEA, novembro de 2000.

${ }^{10}$ INSPIR - Instituto Sindical Interamericano pela Igualdade Racial, Centro de Solidariedade AFL-CIO, DIEESE - Departamento Intersindical de Estatísticas e Estudos Sócio-Econômicos. Mapa da População Negra no Mercado de Trabalho. São Paulo, INSPIR, outubro de 1999; SoARES, S. S. D. O Perfil da Discriminação no Mercado de Trabalho... Op. cit.; HENRIQUES, Ricardo. Desigualdades raciais no Brasil: evolução das condições de vida na década de 90. Textos para Discussão 807, Rio de Janeiro, IPEA, julho de 2001. Para a região metropolitana de São Paulo, ver dados recentes que apontam na mesma direção coligidos a partir da Pesquisa de Emprego e Desemprego - PED, em: FUNDAÇÃo SEADE. Mulher e Trabalho. São Paulo, SEADE, nº 1 (julho de 2000), 2 (janeiro de 2001) e 3 (março de 2001).
} 
Os desafios da eqüidade

ii. Dividindo posição intermediária estão os homens negros $e$ as mulheres brancas, com faixas salariais, na média, quase equivalentes. Em 1989, os homens negros respondiam por salários ligeiramente mais altos; em 1998 as mulheres brancas pareciam ligeiramente melhor remuneradas; ${ }^{11}$

iii. Por fim, na base da hierarquia, vêm as mulheres negras, com salários significativamente menores.

Tais desigualdades de remuneração entre sexos se sobrepõem às vantagens relativas da escolarização feminina (Tabela 6). Na indústria brasileira, as desigualdades salariais convivem com o fato de que as mulheres brancas são, em média, mais escolarizadas que os homens brancos, e que as mulheres negras são também mais escolarizadas que os homens negros.

Podemos refletir, ainda, sobre a importância, para a ampliação desses diferenciais, da exclusão dos negros do acesso à educação superior brasileira. Tal barreira escolar está reiteradamente demonstrada por trabalhos de inequívoca qualidade. $^{12} \mathrm{O}$ que aqui destaco é que uma tão desigual

\footnotetext{
${ }^{11}$ Essa área cinzenta, no que tange a posição intermediária, aclara-se quando refinamos os procedimentos de medida, e a hierarquia passa a coincidir com os achados correntes: no topo, os homens brancos; em seguida, as mulheres brancas; abaixo, os homens negros; e, ao final, as mulheres negras. Para maior desenvolvimento, ver a seção final deste texto e BIDERMAN, Ciro e GUIMARÃES, Nadya Araújo. Desigualdades, discriminação e políticas públicas. Uma análise a partir de setores selecionados da atividade produtiva no Brasil. Comunicação apresentada à Sessão sobre "Flexibilidade, Segmentação e Eqüidade", na II International Conference ILAS-CEBRAP, CEBRAP, São Paulo, 18-20 de março de 2002, 30pp. Esses achados são convergentes com os de MEZZERA, Jaime. Género, raza, empleo e ingresos. Mimeo, s/d, 28 pp.

${ }^{12}$ Rosemberg, Fulvia. Diagnóstico sobre a situação educacional de negros (pretos e pardos) no Estado de São Paulo. São Paulo, Fundação Carlos Chagas, 1986; SiLVA, Nelson do Valle e HaSenBalg, Carlos. Relações Raciais no Brasil Contemporâneo. Rio de Janeiro, IUPERJ/Rio Fundo Editora, 1992; HASENBALG, Carlos. Tendências da desigualdade educacional no Brasil. Dados, vol. 43, n⿳0 3, Rio de Janeiro, IUPERJ, 2000. HENRIQUES, R. Desigualdades raciais no Brasil... Op. cit. MezzeRA, J. Género, raza, empleo e ingresos . Op.cit.
} 
composição escolar, como a que se documenta na Tabela 6, tem, por certo, efeitos no acesso de trabalhadores (negros e negras) às posições de poder - isto é, às posições de mando e chefia superior - que asseguram os bons salários na indústria brasileira e que poderiam minimizar o hiato de rendimentos documentado acima. Sabemos, por vários estudos de caso com respeito a carreiras de trabalhadores na indústria que, no Brasil, à diferença de outros países, a mobilidade em direção a posições de mando está demarcada pela posse de credencial escolar, estando associada à aquisição de títulos universitários. ${ }^{13}$

Tabela 6

Distribuição do emprego na indústria de transformação, por faixas de escolaridade, segundo sexo e raça, em 1998

\begin{tabular}{l|lll|lll}
\hline & \multicolumn{3}{|c|}{ Mulheres } & \multicolumn{3}{c}{ Homens } \\
& Negras & Brancas & Total & Negros & Brancos & Total \\
\hline $1^{\circ}$. Grau Incompleto & 59.7 & 43.5 & 49.0 & 66.6 & 47.8 & 54.9 \\
$1^{\circ}$. Grau Completo & 21.4 & 22.6 & 22.2 & 18.9 & 21.4 & 20.4 \\
$2^{\circ}$. Grau Completo & 17.1 & 26.5 & 23.3 & 13.2 & 23.1 & 19.4 \\
Superior & 1.8 & 7.4 & 5.5 & 1.4 & 7.7 & 5.3 \\
\hline
\end{tabular}
Fonte: PNAD/IBGE

\footnotetext{
${ }^{13}$ Ver, por exemplo, sugestivas considerações de Hirata, comparando os critérios de mobilidade nas carreiras em plantas petroquímicas no Japão (face ao Brasil). Cf. HIRATA, Helena S. Les effets sociaux des grands projets industriels: le pôle pétrochimique de Camaçari (Bahia). Comunicação ao Colloque international Endettement, Grands Projets Industriels et Agricoles, Paris, Ministère de la Recherche, 24-25 fevereiro de 1984. Para o caso brasileiro, destacando o "credencialismo" que nos caracteriza, ver: DinIz, Marli. Os Donos do Saber Profissóes e Monopólios Profissionais. Rio de Janeiro, IUPERJ/Revan, 2000; AgIER, Michel; CASTRo, Nadya Araújo; GuimarâES, Antonio Sergio. Imagens e Identidades do Trabalho. São Paulo, Hucitec, 1995; MEzzERA, J. Género, raza, empleo e ingresos . Op.cit.
} 
Os desafios da eqüidade

Isto parece nos levar a um novo desafio analítico. Mapeadas as desigualdades, e documentada a sua persistência, mesmo em contextos sob intensa reestruturação, algumas indagações de pesquisa se tornam prementes - e é exatamente a elas que se dedica a segunda parte desse trabalho.

\section{Desigualdades e discriminações}

Dois alvos principais mobilizarão o argumento a partir de agora. Primeiro: poder-se-ia admitir que as desigualdades, até aqui indicadas, esconderiam uma efetiva discriminação, expressa nas oportunidades e no tratamento no trabalho, discriminação essa fundada em critérios socialmente adscritivos, que desvalorizariam atributos de sexo ou raciais? Segundo: é possível diferenciar padrões de desigualdade, que particularizariam as situações de despartido vivenciadas por homens negros, por mulheres brancas ou por mulheres negras; isto é, há uma diversidade na forma como desigualdade e discriminação atingem grupos de sexo e cor no Brasil?

Esses dois alvos se traduzem em alguns interrogantes principais. Como descrever com mais precisão os padrões específicos que assumem essas desigualdades, caracterizando melhor a sua natureza: que barreiras atingem as mulheres negras? Diferenciam-se essas das que atingem as mulheres brancas ou os homens negros? Por outro lado, como avançar na identificação dos fatores determinantes dessa desigualdade? Isto é, quanto da desigualdade hoje manifesta resulta de desvantagens sociais mais amplas acumuladas (e este é o caso, por exemplo, do acesso à escolarização) e quando expressa verdadeiramente o peso da discriminação, a prevalência de barreiras ou de formas de segregação fundadas no racismo ou no sexismo? Em que grupos, e por quais mecanismos, as desigualdades resultam de processos de discriminação?

Isso nos desafia a avançar no estudo dos determinantes dessas diversidades, levando adiante - e, sobretudo, articulando - 
Nadya Araújo Guimarães

as indagações até aqui formuladas pelos estudos de gênero por um lado, ou pelos estudos de relações raciais, por outro. Isto porque a parte mais expressiva da nossa literatura dedicou-se a refletir sobre a existência de padrões de desigualdade que diferenciariam homens, por um lado, e mulheres, por outro; ou brancos, por um lado, e negros, por outro. ${ }^{14}$

Continuarei tomando os rendimentos como o território crítico para refletir sobre a existência de padrões de desigualdades. Com base neles posso, como vinha fazendo anteriormente, interpelar os dados da realidade brasileira em termos de qual seria o preço da posse de certos atributos: quanto custa ser mulher? quanto custa ser negro? Utilizo, como inspiração, o trabalho pioneiro de Silva e o mais recente de Soares. ${ }^{15}$ Comparo as diferenças salariais entre os rendimentos dos homens brancos, por um lado, e cada um dos outros grupos que supomos, pelos dados anteriores, possam estar sujeitos a alguma sorte de discriminação os homens negros, mulheres brancas e mulheres negras. ${ }^{16}$

${ }^{14}$ Confirmando a regra, algumas exceções importantes propugnaram no sentido de associar a análise das desigualdades de sexo e de cor. Créditos lhes devem ser reconhecidos por seu esforço precursor, tanto no âmbito da economia quanto da sociologia do trabalho. Destaco, entre eles: ROSEMBERG, F. Diagnóstico sobre a situação educacional de negros (pretos e pardos)... Op.cit; OLIVEIRA, Lucia Elena. Repensando o lugar da mulher negra. Estudos Afro-Asiáticos, n 13, 1987, pp 87-109; BAIRROS, Luiza. Mulher negra: o espaço da subordinação. In: LOVELL, Peggy. (org.) Desigualdade racial no Brasil contemporâneo. Belo Horizonte, CEDEPLAR, 1991, pp 177-193; Raça, classe, gênero e discriminação salarial no Brasil. Estudos Afro-Asiáticos, no 22, set. de 1992, pp 85-98; ABREU, A; JORGE, A; SoRJ, B. Desigualdade de gênero e raça... Op.cit.; INSPIR e DIEESE. Mapa da População Negra... Op.cit.; SoARES, S. O Perfil da Discriminação... Op.cit.; HENRIQUES, R. Desigualdades raciais no Brasil... Op. cit.

${ }^{15}$ SILVA, Nelson do Valle. O preço da cor: diferenciais raciais na distribuição de renda no Brasil. Pesquisa e Planejamento Econômico, vol. 10, n 1, 1980, pp 21 44; SoARES, S. S. D. O Perfil da Discriminação... Op. cit.

${ }^{16}$ Nesta seção do texto antecipo, na forma de alguns resultados gerais, parte de uma análise mais detalhada que se encontra em Biderman e Guimarães, onde (lançando mão do mesmo método de decomposição de Oaxaca, também utilizado por Soares) comparamos padrões de segregação por sexo e cor em 
Os desafios da eqüidade

Para responder à primeira indagação, e documentar a existência da discriminação de sexo e/ou de cor como um fator determinante da distância entre salários, controlo os efeitos de algumas possíveis variáveis, que sabemos são igualmente intervenientes e que também podem explicar a desigualdade salarial. São elas:

a) outras características do trabalhador ou trabalhadora, que se configurem em ativos, que os diferenciariam na competição por emprego e salários, como qualificação escolar ou senioridade ${ }^{17}$

b) sua inserção geográfica, ou seja, a região onde o trabalhador ou trabalhadora exerce seu trabalho, de modo a controlar efeitos que possam resultar da diversidade de níveis de remuneração nos distintos subespaços do mercado de trabalho no Brasil. Isto porque, sabemos, por exemplo, que os negros concentram-se em regiões (como o Nordeste, que reúne nada menos que $40 \%$ deles) onde padrões salariais são menores; assim sendo, alguém poderia argüir que a desvantagem salarial seria resultante não da condição racial, mas da sua inserção regional;

c) sua inserção setorial, controlando efeitos dos padrões salariais vigentes nos diversos setores da atividade econômica onde trabalhadores e trabalhadoras exercem um posto de trabalho;

d) o estatuto do vínculo de trabalho; isto porque, é fato que os trabalhadores no setor formal têm um padrão de remuneração superior, em média, aos que não possuem vínculo formalizado - $e$

setores selecionados da indústria no Brasil. BIDERMAN, C. e GuimARÃES, N. A. Desigualdades, discriminação e políticas públicas... Op. cit.; OAXACA, Ronald. Male-female wage differentials in urban labor markets. International Economics Review, vol. 14, nº 3, 1973.

${ }^{17}$ Operacionalizadas por meio de duas variáveis (anos de estudo e idade), e posteriormente combinadas, elas aparecerão referidas sob o nome de "qualificação". 
sabemos que negros e mulheres estão mais fortemente ocupados em empregos não registrados e precários ${ }^{18}$;

e) finalmente, o tipo de ocupação em que atua o trabalhador ou a trabalhadora. Outra vez, sabemos que o prestígio das ocupações varia e que a composição por sexo e cor das mesmas pode estar a ele associada. Controlando os efeitos dessa variável, mediante a construção de uma classificação ocupacional hierarquicamente estruturada, penso ser possível confrontar o argumento de que os salários seriam mais baixos não por discriminação de sexo ou racial, mas por um possível efeito de auto-segregação que orientaria as escolhas de trabalhadores $e$ trabalhadoras, dirigindo-os/as para nichos ocupacionais de mais baixos salários (onde se sentiriam mais seguros/as para competir).

Naturalmente, por se tratar de uma análise de determinantes das desigualdades nos ganhos, apenas os trabalhadores $e$ trabalhadoras com rendimentos positivos foram considerados como parte do universo empírico que tratarei daqui por diante. Assim, como há diferenças importantes entre homens e mulheres no que concerne ao número de horas trabalhadas ${ }^{19}$, os rendimentos serão tratados em termos de salário-hora, de modo a controlar o efeito desse fator sobre os níveis de ganhos. Sigo trabalhando com a mesma base de dados, a PNAD, e tomo em conta o ano de 1999, o mais recente em termos da disponibilidade de dados. Utilizarei, como ferramenta, a análise de regressão, de modo a decompor os efeitos e o peso de diferentes variáveis determinantes das desigualdades, e estimar o custo dos atributos

\footnotetext{
${ }^{18}$ Abreu, A.; Jorge, A.; SorJ, B. Desigualdade de gênero e raça... Op. cit.; Guimarães, N. A. e CONSONI, F. L. As Desigualdades Reestruturadas... Op. cit.; LAVINAS, Lena. Diferenciais de rendimentos entre homens e mulheres nas áreas metropolitanas. Rio de Janeiro, mimeo., 1998.

${ }^{19}$ Como as mulheres trabalham em média menos horas que os homens, poderse-ia argüir que o menor rendimento resultaria também do menor número de horas trabalhadas.
} 
Os desafios da eqüidade

de sexo e cor em termos dos rendimentos auferidos por trabalhadores e trabalhadoras.

Tabela 7

Decomposição dos determinantes das diferenças entre os rendimentos dos grupos de sexo e cor na população ativa

(Brasil, 1999)

\begin{tabular}{|r|r|r|r|r|r|r|}
\hline & \multicolumn{2}{|c|}{$\begin{array}{c}\text { Homens } \\
\text { Negros }\end{array}$} & \multicolumn{2}{|c|}{$\begin{array}{c}\text { Mulheres } \\
\text { Brancas }\end{array}$} & \multicolumn{2}{c|}{$\begin{array}{c}\text { Mulheres } \\
\text { Negras }\end{array}$} \\
\hline & $\mathrm{R} \$$ & $\%$ & $\mathrm{R} \$$ & $\%$ & $\mathrm{R} \$$ & $\%$ \\
\hline Salário Referência & 5,11 & & 5,11 & & 5,11 & \\
\hline Qualificação & 1,55 & $58,3 \%$ & $-1,00$ & $-113,7 \%$ & 0,75 & $25,0 \%$ \\
\hline Inserção formal & 0,07 & $2,6 \%$ & 0,45 & $51,8 \%$ & 0,49 & $16,1 \%$ \\
\hline Inserção regional & 0,27 & $10,3 \%$ & 0,07 & $8,3 \%$ & 0,36 & $11,9 \%$ \\
\hline Inserção & & & & & & \\
ocupacional & 0,07 & $2,8 \%$ & 0,01 & $1,1 \%$ & 0,05 & $1,7 \%$ \\
\hline Discriminação & 0,37 & $13,8 \%$ & 1,18 & $134,6 \%$ & 1,00 & $33,1 \%$ \\
\hline Resíduo & 0,33 & $12,3 \%$ & 0,16 & $18,1 \%$ & 0,37 & $12,2 \%$ \\
\hline Salário do grupo & 2,46 & & 4,23 & & 2,10 & \\
\hline
\end{tabular}

Fonte: PNAD

Tal como Soares, tomo a remuneração dos homens brancos como referência, não apenas por ser a mais elevada, mas por referir-se ao grupo de trabalhadores que possui atributos de sexo (são homens) e de cor (são brancos) que não parecem atuar depreciando o preço do seu trabalho. É com relação ao seu salário-hora médio, em 1999 , de $\mathrm{R} \$ 5,11^{20}$, que se estabelece a comparação com os outros grupos, que lhe são desiguais ${ }^{21}$ : homens negros (que recebem $\mathrm{R} \$ 2,46$ em média por hora),

${ }^{20}$ Vide linha primeira da Tabela 7 ("Salário referência").

${ }^{21}$ Os rendimentos médios por hora dos demais grupos (homens negros, mulheres brancas e mulheres negras) estão indicados na última linha da Tabela 7 ("Salário do grupo"). 
Nadya Araújo Guimarães

mulheres brancas (pagas, em média, a $\mathrm{R} \$ 4,23$ por hora trabalhada) e mulheres negras (percebendo apenas $\mathrm{R} \$ 2,10$ a cada hora de trabalho). A análise de regressão nos permitirá determinar o peso dos determinantes dessa desigualdade. Na Tabela 7 estimase o quanto da distância entre o salário do grupo em questão e o salário de referência (os homens brancos) pode ser creditado a cada um desses diferentes fatores.

De modo a tornar os números mais atraentes e densos em significado para o leitor, a Tabela 7 traduz cada um dos componentes explicativos das desvantagens em fração de salário não recebido e que poderia ser a ele atribuída. Vemos, por exemplo, que dos $\mathrm{R} \$ 2,65$ que os homens negros deixam de receber, a maior parte, nada menos que $\mathrm{R} \$ 1,55$ resulta do diferencial de qualificação que os separa dos homens brancos; apenas $\mathrm{R} \$ 0,33$ parecem ser exclusivamente explicados por sua condição racial.

Assim, analiticamente, o primeiro olhar se dirige para verificar o quanto o rendimento-hora varia (i) em vista de cada uma de quatro variáveis que tomo como possíveis fatores explicativos de desigualdades de rendimentos face aos homens brancos (qualificação, inserção formal, inserção regional, inserção ocupacional), e (ii) em quanto o rendimento/hora pode variar em função da pura e simples condição de sexo ou de cor, isto é, de fatores que desigualam os indivíduos em base à clara "discriminação", produzindo um efeito de segregação. ${ }^{22}$

Ao fazê-lo, vê-se que é entre as mulheres que o fator discriminação parece ser mais ponderável. Mas é entre as brancas que ele parece ter um peso decisivo. Isto porque no caso das mulheres negras outras formas de desvantagem relativa são igualmente atuantes. Assim, apesar dos significativos ganhos de escolaridade (registrados anteriormente), as mulheres negras ainda

\footnotetext{
${ }^{22}$ Notar que, além dessas há uma penúltima linha na Tabela 7 , denominada "resíduo", que corresponde àquela parte da variação do salário-hora que não se explica por qualquer das variáveis incluídas no modelo.
} 
Os desafios da eqüidade

têm problemas com respeito a sua qualificação escolar, que explicam grande parte $(25 \%)$ do seu despartido salarial. Por certo, os atributos de sexo e cor (ser mulher e ser negra), na forma como são socialmente desvalorizados, ainda explicam a maior parte da desigualdade salarial (33\% da diferença face aos salários médios dos homens brancos); mas a eles se soma todo um leque de fatores, a maioria dos quais fruto de desigualdades sociais geradas fora do mercado de trabalho (sua menor escolaridade, o fato de competir em mercados que pagam menores salários), mas com efeitos diretos nos rendimentos auferidos pela trabalhadora negra. ${ }^{23}$

$\mathrm{O}$ que acontece com as mulheres brancas? Por que exatamente entre elas o peso líquido da discriminação é maior? Exatamente pelo fato de que esse grupo parece dispor de todos os outros ativos (gerados no contexto social mais amplo) que propiciariam a eqüidade face aos rendimentos dos homens brancos. Sua escolaridade não somente é elevada, mas é significativamente mais elevada que a dos homens brancos. ${ }^{24} \mathrm{~A}$ eles se equivalem pela idade média, pela freqüência com que possuem carteira de trabalho; disputam empregos nos mesmos mercados regionais de trabalho onde são melhores as remunerações (Sul e Sudeste); estão presentes nos setores de atividade onde melhor se paga e nas posições de prestígio

\footnotetext{
${ }^{23}$ Reconhecer este tipo de composição de fatores é extremamente importante, pois acena para a necessidade de um leque de políticas: políticas de cunho universalista (que melhoram as condições sociais dos mais pobres), mas focalizadas e compensatórias (que afetam os problemas que atingem específica e exclusivamente as mulheres negras); políticas sociais de largo espectro, ao lado de políticas voltadas para os ambientes de trabalho (onde a discriminação de sexo e raça parece ainda afetar as diretrizes de gestão de recursos humanos).

${ }^{24} \mathrm{Em}$ 1999, conforme os dados da PNAD, para este segmento de trabalhadores com rendimentos positivos, as mulheres brancas tinham quase 9 anos de estudos em média $(8,62)$, contra apenas 7 dos homens brancos $(7,2)$; destes, aproximavam-se as mulheres negras, com 6,2, distantes significativamente dos homens negros, que tinham, em média, apenas 4,2 anos de estudos.
} 
Nadya Araújo Guimarães

ocupacional onde também são melhores os rendimentos. Aparentemente, sua única e significativa desvantagem na competição por rendimentos parece estar inscrita no corpo - e não preponderantemente em desigualdades de origem social mais ampla -, sua condição de sexo as desqualifica na disputa por melhores salários.

E quanto aos homens negros? Em comum com as mulheres negras, e diferentemente das mulheres brancas, seu despartido face ao grupo de referência (os homens brancos) pode ser explicado por um cardápio de fatores. Entretanto, esse cardápio parece mais restrito que o das mulheres negras: ao lado do peso decisivo da baixa qualificação escolar, destaca-se apenas sua retenção em mercados de trabalho onde pior se remunera. Embora subsista algum efeito creditável à discriminação racial, são essencialmente os fatores sociais mais amplos que explicam a desigualdade de rendimentos. É a desigualdade gerada fora e préexistente ao mercado de trabalho que nele lança seus efeitos, explicando a distancia nos rendimentos, mais que a discriminação produzida nos locais de trabalho.

Isto permite consolidar duas conclusões. ${ }^{25} \mathrm{Em}$ primeiro lugar, documentamos, de modo estatisticamente contundente, com ferramenta robusta e para o conjunto da força de trabalho ocupada no Brasil, a prevalência de mecanismos de alocação de salários e rendimentos baseados única e exclusivamente em critérios adscritos, fundados na discriminação, de sexo e racial. Em segundo lugar, tais mecanismos atingem de maneira desigual os próprios grupos sujeitos à desigualdade de rendimentos, configurando - $e$ isto é importante em termos analíticos, mas, sobretudo, em termos políticos - padrões diferenciados de desigualdades, que afetam os grupos discriminados. O gráfico 1 retrabalha os dados da Tabela 7 de modo a deixar mais claros esses padrões de que tratamos acima.

${ }^{25}$ Que reforçam achados anteriores, notadamente de SOARES, S. S. D. O Perfil da Discriminação no Mercado de Trabalho... Op. cit. 
Os desafios da eqüidade

Algumas considerações adicionais ainda nos parecem necessárias, de modo a melhor comentarmos esses achados. Em primeiro lugar, eles parecem indicar que, após uma década de intensas transformações nas estratégias empresariais e de gestão do trabalho, o moderno capitalismo brasileiro recria a desigualdade, re-valorizando - isto é, valorando sob formas distintas - antigos demarcadores de tipo adscritivo que afetam as condições de inclusão no trabalho: como seriam a condição de sexo e a condição racial. Nesse sentido - reitero -, esses demarcadores estão longe do ideário da cultura gerencial moderna, fundada na performance, no desempenho dos agentes, em características aquisitivas, enfim.

Em segundo lugar, se sabemos que a reestruturação intensifica a seletividade (e temos isto claramente documentado para os estudos das desigualdades entre grupos de sexo, por exemplo) ${ }^{26}$, os dados antes analisados parecem sugerir que tal seletividade não apenas pode se estabelecer em base a critérios discriminatórios, mas que se alteram os padrões de desigualdade $e$ discriminação a que estão sujeitos os grupos subalternos por seus rendimentos.

Por isto mesmo, e em terceiro lugar, parece cabível afirmar que a seletividade se opera a partir de uma combinação de ativos individuais, antes que apenas sobre uma única característica condição de sexo ou condição racial.

Em quarto lugar, e com isto creio que nos aproximamos a uma especificidade do caso brasileiro, entre os grandes fatores explicativos das desigualdades - que estão na base dos processos de discriminação, seja ela produzida diretamente nos locais de trabalho ou em espaços sociais mais amplos e neles refletida sobressaem-se fatores de adscrição, cujos demarcadores estão

${ }^{26}$ Ver LAVINAS, L. Diferenciais de rendimentos entre homens e mulheres... Op. cit.; GuimARÃES, Nadya Araújo. Laboriosas, mas redundantes: gênero e mobilidade no trabalho no Brasil dos anos 90. Estudos Feministas, vol.9, no 1 , 2001. 
inscritos no corpo, na aparência física dos indivíduos. São marcas de corpo, socialmente valoradas e transformadas em elementos de qualificação (ou desqualificação) social, de qualificação (ou desqualificação) para o trabalho.

\section{Gráfico 1}

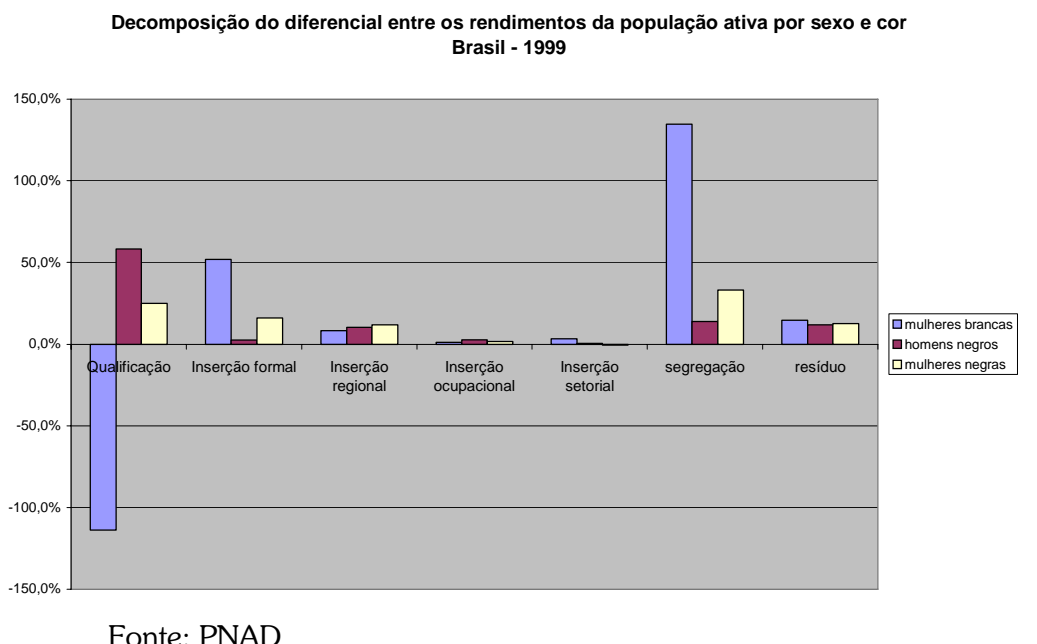

Nesse sentido, torna-se essencial desvendar as formas como as representações sociais sobre as diferenças de corpo se expressam e se recriam no espaço simbólico das relações sociais no trabalho. A literatura brasileira tem dado, até aqui, passos importantes no que concerne à identificação dos mecanismos de discriminação que substituem negros por brancos, mulheres por homens, em oportunidades ocupacionais melhor remuneradas, nos empregos de melhor qualidade, ou em carreiras profissionais exitosas. $^{27}$ Haveria, agora, que inquirir se - e como - os

${ }^{27}$ Cito como exemplo o estudo de Silva, onde se documenta que a introdução da automação micro-eletrônica no pesado trabalho operacional de fornos em 
Os desafios da eqüidade

mecanismos de discriminação, ao assumirem a forma de demarcadores inscritos no corpo dos indivíduos, podem vir a incorporar as marcas da intolerância e/ou da violência entre grupos sociais.

De fato, esse é um território sensível para a reflexão brasileira. Exatamente porque nos acreditamos um modelo de democracia racial, e porque fundamos nossa identidade nacional (entre outros elementos) num ideal de mestiçagem, nem nos

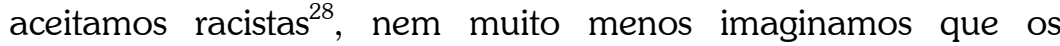
comportamentos discriminatórios possam conter e/ou exercer a intolerância. Intolerância tomada aqui na sua acepção mais forte em que a representação do outro o destitui do sentido de semelhante, do sentido de humanidade compartilhada que constitui um território comum para a relação social entre um ego

empresa siderúrgica brasileira implicou na substituição dos negros operadores dos fornos manuais, por "morenos" ("brancos da terra") operadores dos fornos a comando numérico. Por certo, a escolaridade técnica completa pode estar na superfície da justificativa; entretanto, na instigante etnografia de empresa conduzida pela autora, fica evidente que outros códigos de reconhecimento eram importantes como demarcadores da identidade dos novos trabalhadores "morenos", cuja equipe de futebol foi rapidamente denominada, pelos demais trabalhadores, de "os paquitos da elétrica" (por remissão ao conjunto de louros cantores - "paquitos" - que acompanhavam conhecida atriz, também loura, condutora à época de programa infantil de enorme sucesso no Brasil). SILVA, Paula Cristina. Negros à Luz dos Fornos. Dissertação de mestrado, Programa de Sociologia da UFBa, Salvador, 1995. Sobre diferenciais na mobilidade nas carreiras, ver GUIMARÃES, Antonio Sergio e CASTRO, Nadya Araújo. Desigualdades raciais no mercado e nos locais de trabalho. Estudos AfroAsiáticos, no 24, setembro de 1993, pp.23-61.

${ }^{28}$ Nunca é demais aludir ao resultado de recente pesquisa de opinião de caráter nacional (Datafolha) onde foi encontrado que, embora uma significativa maioria dos indivíduos considerasse que os brasileiros discriminavam, era absolutamente insignificante o número dos que se reconheciam como tendo, alguma vez, exercido conduta discriminatória. Ou seja, a discriminação (sob a forma do racismo ou do sexismo) é sempre sustentada em atos que estão fora dos sujeitos, que são condutas de um outro desencarnado. 
qualquer $e$ um alter que lhe seja socialmente significativo. ${ }^{29}$ Intolerância, nesse sentido, é parceira, ou quando menos antesala, da violência.

Ora, nossa literatura sobre relações raciais tem destacado, notadamente no caso dos negros, os processos de violência simbólica que, ao longo da construção recente da sociedade brasileira, estabeleceram "o lugar do negro" no espaço público das relações sociais. ${ }^{30}$ Assim, a literatura (da sociologia, mas também da psicologia) tratou de maneira cuidadosa dos mecanismos de internalização da discriminação, de autosegregação, enquanto cimento poderoso a sedimentar os efeitos da discriminação racista ou sexista. Fontes para a construção de um ideal de ego e, nas quais, a violência encontra lugar no âmbito simbólico.

Só muito recentemente, entretanto, passamos a ter evidências suficientes de modo a inquirir sobre aspectos da reprodução dessa violência - sob a forma da intolerância, da humilhação e, por vezes, da violência física -, nos espaços públicos e, dentre eles, nos espaços do trabalho. ${ }^{31}$ Análise empírica pioneira foi realizada por Guimarães ${ }^{32}$, que revisou os registros tomados durante um ano, entre maio de 1997 e abril de 1998, na Delegacia de Crimes Raciais da cidade de São Paulo. E

\footnotetext{
${ }^{29}$ HÉRITIER, Françoise. Les fondements de la violence. Comunicação apresentada no Seminário La Violence, les Mots et le Corps, Paris, IRESCO/GERS, 2001.

${ }^{30}$ Ver Hasenbalg, C. e Silva, N. V. Estrutura Social Mobilidade e Raça. São Paulo/Rio de Janeiro, Vértice/Iuperj, 1988 (Coleção Grande Brasil, Veredas; v.7).

${ }^{31}$ De fato, no Brasil, somente após a lei 7.716, de 1989, definiu-se normativamente o que seria crime racial. Desde então, ativistas e advogados negros têm sido atraídos por uma curiosa persistência - a maioria das queixas de discriminação formalmente registradas seria enquadrável como crimes de injúria e infâmia. Isso levou a uma modificação no Código Penal (lei 9459), que passou a facultar a punição da injúria racial com o mesmo rigor que os demais crimes raciais. Para uma remissão detalhada ver GuIMARÃES, Antonio Sergio. O insulto racial. Estudos Afro-Asiáticos, n 38 , dezembro de 2000.

${ }^{32}$ ID., IB.
} 
Os desafios da eqüidade

em que a sua análise nos importa? Revisando-a, à luz das considerações anteriores, sobressaem-se alguns achados instigantes que animam a discussão sobre os elos entre discriminação, racismo/sexismo, intolerância e formas de violência no trabalho no Brasil.

O primeiro aspecto a chamar a atenção é que, dentre todos os espaços onde tiveram lugar os conflitos raciais (registrados como queixas), o âmbito do trabalho surge como aquele que provê a maior quantidade de registros nas Delegacias de Crimes Raciais. Foram $40 \%$ das queixas formuladas em um ano, o que equivale a pouco mais que a soma dos dois outros âmbitos igualmente relevantes, quais sejam, os espaços de consumo e os espaços das relações de vizinhança.

Em segundo lugar, o insulto racial, ou seja, a violência que se expressa no trabalho, na forma da intolerância pelo outro, não é um recurso final que resulta de um crescendo de antagonismo $e$ desentendimento entre os agentes. Ao contrário, é ele que instala o conflito. Ou seja, a desqualificação do outro, como atitude inaugural da intolerância na relação social no trabalho, parece uma forma de violência que pretende colocar o interlocutor "no seu lugar", humilhando-o. Mas há um outro fato ainda mais interessante. No relato que o autor apresenta sobre as situações em que tal intolerância se expressa, conforme o registro feito constar pelas vítimas, o insulto tem lugar sempre quando clientes ou usuários de serviços interagem com agentes prestadores que são trabalhadores/as negros/as. O insulto parece exprimir, assim, a inconformidade com a igualdade social de negros, expressa na forma como estes desempenham os seus papéis no trabalho.

Conseqüente com isto, encontra-se, ainda, nos dados desse estudo, que as queixas no trabalho não se restringem a negros ou negras em posições de baixa qualificação. Ao contrário, elas estão documentadas também no trato entre posições hierarquicamente superiores, e mesmo entre empresas, como um exemplo citado de injúria registrada no trato entre gerentes de duas empresas 
Nadya Araújo Guimarães

associadas (cliente, uma delas, e fornecedora de serviços, a outra). Entretanto, e cito o autor:

Dependendo do grau de segurança do ofensor quanto à sua própria posição social, os insultos podem apenas sugerir a animalização ou coisificação dos negros (quando o reconhecimento social do ofensor é visível), mantendo-se no terreno da desqualificação social, ou podem progredir para uma completa negação da humanidade do ofendido, situação mais comum quando a distância social entre ofendidos e ofensores é mínima. ${ }^{33}$

Finalmente, sabemos, com os dados gerais sobre as ofensas registradas, que são as mulheres negras as mais insultadas, o que sugere um importante (e quem sabe esperado) entrecruzamento entre sexo e cor. Sem embargo, o que instiga observações $e$ análises suplementares é um outro achado: mulheres ofendem mais as próprias mulheres e homens os próprios homens.

Ora, sabemos que os efeitos do racismo e do sexismo podem advir do exercício do preconceito, da discriminação e da intolerância, mas podem também resultar da internalização de expectativas de comportamento que tem no próprio sujeito o instrumento para fixar os graus de liberdade que se abrem a suas ações no âmbito do trabalho. Hasenbalg ${ }^{34}$ já havia chamado a atenção para a violência simbólica que se exerce sobre os negros, no Brasil, na forma da internalização da inferioridade; muitos estudos no campo do feminismo têm documentado os efeitos da internalização das expectativas de comportamento "feminino" contidas nos papéis sociais de gênero. Por certo, a associação entre ambas constelações de expectativas de conduta contribui para consolidar os efeitos de segregação e desigualdade no

\footnotetext{
${ }^{33}$ ID., IB.

${ }^{34}$ Hasenbalg, C. e Silva, N. V. Estrutura Social Mobilidade e Raça. Op.cit.; Silva, N. V. e HaSEnBALG, C. Relações Raciais no Brasil... Op. cit.
} 
Os desafios da eqüidade

trabalho. Urgem, então, estudos qualitativos suplementares sobre a construção das decisões e a representação da desigualdade de sexo e de cor entre os/as próprios/as trabalhadores/as.

Tomados em conjunto, os dados e considerações aqui apresentados atiçam nossa agenda investigativa, desafiando-a a ir mais além em suas ambições temáticas, teóricas e metodológicas. Ir mais além não apenas no sentido de desvelar a discriminação que se esconde por detrás das estatísticas de desigualdades; de não apenas mostrar que são diversos os padrões de discriminação que atingem diferentes sujeitos (os quais são uma síntese de características, distintas por seu significado no quadro dos demarcadores sociais das qualidades subjetivas). Esses dados nos atiçam a avançar no estudo dos mecanismos de expressão do racismo e do sexismo no trabalho, articulando nossas teorizações sobre desigualdades ocupacionais, sobre organização do trabalho e sobre subjetividade dos atores aos achados nos campos de estudos das relações de gênero e relações raciais. Isto nos obrigará a renovar metodologicamente nossas abordagens do trabalho, seja em termos da construção dos nossos objetos, seja em termos das formas pelas quais a eles teremos acesso em termos operacionais. Sem esses avanços dificilmente poderemos progredir do conhecimento preciso às medidas dirigidas às almejadas (e efetivas) políticas de eqüidade. 